\title{
Multiple choice criteria and the dynamics of assortative mating during the first breeding season of female snow crab Chionoecetes opilio (Brachyura, Majidae)
}

\author{
B. Sainte-Marie ${ }^{1, *}$, N. Urbani ${ }^{2}$, J.-M. Sévigny ${ }^{1}$, F. Hazel ${ }^{1}$, U. Kuhnlein ${ }^{2}$ \\ ${ }^{1}$ Division des invertébrés et de la biologie expérimentale, Institut Maurice-Lamontagne, Ministère des Pêches et des Océans, \\ 850 route de la Mer, CP 1000, Mont-Joli, Québec G5H 3Z4, Canada \\ ${ }^{2}$ Department of Animal Science, McGill University, Macdonald Campus, Sainte-Anne-de-Bellevue, Québec H9X 3V9, Canada
}

\begin{abstract}
Crab pairs, consisting of a male grasping another crab (the graspee), were collected by divers during the first breeding season of female snow crab Chionoecetes opilio. Different types of graspees were found and were ranked according to their reproductive value to the male. High-value graspees were pubescent females (close to their terminal maturity molt) and nulliparous females (just molted and close to oviposition). Postmolt primiparous females (clean-soft shell and carrying eggs) also mated anc were inseminated by males, but they were of less value than pubescent or nulliparous females as there was only a remote chance that the males' stored sperm would be used to fertilize the next egg clutch. Females copulated with up to 6 different males during their first breeding season. Another category of graspees including males and juvenile females provided the grasping male with no fecundity benefit. Pubescent females paired with males up to $13 \mathrm{~d}$ before molting. Males grasping the high-value pubescent and nulliparous females were larger, had a harder shell, and were missing fewer limbs than the males grasping low-value primiparous females, other males or juvenile females and than the overall population of adult males on the mating grounds assessed by trawl. Size-assortative mating by male chela size and female carapace width occurred in the predominant pubescent pairs. Moreover, males with larger chelae were associated with pubescent females missing fewer limbs or having relatively narrower abdomens. Both traits may influence female survivorship and lifetime fecundity. The complex assortative mating pattern of snow crabs apparently derives from mate choice and male sexual competition in the context of prolonged attractiveness of pubescent females to males
\end{abstract}

KEY WORDS: Snow crab · Chionoecetes opilio - Mating system - Sexual competition - Mate selection Polyandry $\cdot$ Microsatellite

\section{INTRODUCTION}

Size-assortative mating represents a positive correlation between the body size of paired females and males. This pattern occurs in many marine arthropods. Hypotheses to explain size-assortative mating in arthropods were reviewed by Crespi (1989) and fall into 3 broad categories: (1) size-dependent physical or

·E-mail: sainte-marieb@dfo-mpo.gc.ca energetic constraints that limit the size of mate that can be handled, (2) spatial or temporal patterns of covariation in the size of receptive females and males, and (3) preference and choice of large mates in the context of sexual competition. Ridley (1983) proposed that size-assortative mating arises when there is a fecundity benefit in choosing a larger mate, a size advantage in competition for mates, and prolonged pair bonds

In Brachyura, the mating male often carries the female (Christy 1987) and correlations between the body size of paired females and males are usually 
weak or null (e.g. Reid et al. 1994). Assuming that males choose their mates, the weakness of size correlations in some species has been attributed to the fact that female body size is a poor predictor of fecundity (Jivoff 1997). However, males may also choose females on the basis of their proximity to maturity molt (Jivoff \& Hines 1998) or oviposition (Diesel 1988), which are features that are independent of fecundity, to maximize their number of progeny by mating briefly with more females. An alternative or complementary explanation for the weakness of size-assortative mating patterns is that male body size is a poor predictor of the outcome of sexual competition (Smith et al. 1994).

Among brachyurans, the snow crab Chionoecetes opilio is one of the better studied species from the perspective of reproductive biology (Elner \& Beninger 1992, 1995). Five snow crab life history features make it an interesting model species for the study of sizeassortative mating:

(1) Both sexes undergo a terminal molt. In females, the terminal molt marks the onset of adulthood in the course of a complex life history (Fig. 1) and is accompanied by an enlargement of the abdomen to accommodate the eggs. Females are called pubescent prior to their terminal molt when they begin to attract males, nulliparous after their terminal molt but before oviposition, and primiparous after terminal molt and first oviposition. Adult females are iteroparous and oviposit once annually, or biennially. After the second oviposition, females are called multiparous. In eastern Canada, pubescent and multiparous females come into breeding season at different times of the year, that for the former from December to April and that for the latter from May to June.

In males, the terminal molt marks the passage from adolescence to adulthood and results in a disproportionate increase in chela size relative to carapace size (Conan \& Comeau 1986, Sainte-Marie et al. 1995). Large chelae provide adult males with added strength for carrying a female, an activity that may depend on the male's exoskeleton being hard (Conan \& Comeau 1986). Adult males usually outcompete adolescent males (i.e. sperm-producing, but not yet terminally molted) of similar body size and shell condition in contests for females (Claxton et al. 1994, Sainte-Marie et al. 1997). After the terminal molt, females and males eventually become senescent and die over a period of about 5 to 6 yr (Sainte-Marie et al. 1995, Alunno-Bruscia \& Sainte-Marie 1998).

(2) Pubescent, nulliparous, postmolt (i.e. with a cleansoft shell) primiparous, and multiparous females can be distinguished by a trained observer. This distinction provides a basis for investigating mating associations by female age and condition.

(3) There is a strong correlation between clutch size and body size of primiparous females (Sainte-Marie \&

\section{FEMALE LIFE HISTORY}

\section{PHASES \\ duration Events}

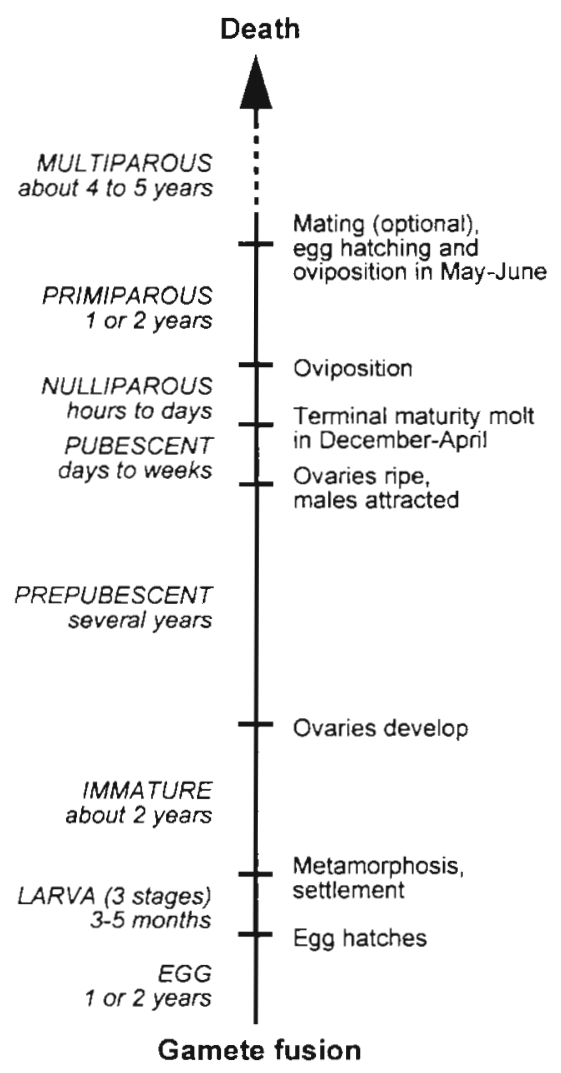

Fig. 1. Chionoecetes opilio. Schematic of female life history based on studies by Alunno-Bruscia \& Sainte-Marie (1998) Bouchard et al. (1996) and Sainte-Marie (1993). Juvenile females are the immature and prepubescent phases, adult females are the nulliparous, primiparous and multiparous phases. The pubescent female is a transitional phase between the juvenile and the adult female. The number of ovipositions realized by a female after terminal molt varies from $2-3$ to about 5 , depending on incubation time ( 1 or 2 yr) for eggs held beneath the abdomen

Lovrich 1994), so female body size is a good predictor of fecundity benefits to males. In the genus Chionoecetes, primiparous females are about 70 to $80 \%$ as fecund as non-senescing multiparous females of equal body size (Somerton \& Meyers 1983, Sainte-Marie 1993).

(4) Reproductive behaviors are complex. Males are polygamous and may guard females before (Watson 1972) and after (Sainte-Marie et al. 1997) copulation. Pubescent females attract males by way of pheromones (Bouchard et al. 1996) and, once molted, can copulate several times shortly before and after extruding their eggs with the same male (i.e. repeated mating) or with different males (i.e. multiple mating) (Sainte-Marie et al. 1997. Urbani et al. 1998a). In multiple-mated nulli- 
parous females, stratification of rival sperm and positional advantage of most recently deposited sperm within the female reproductive tract confer paternity on the last male to inseminate a female before oviposition (Urbani et al. 1998a). Sperm deposits can be stored in the female's spermathecae over several years, for autonomous fertilization of subsequent egg clutches in the absence of males (Kon \& Sinoda 1992, Elner \& Beninger 1995, Sainte-Marie \& Carrière 1995).

(5) Populations may exhibit cyclic recruitment patterns that cause the abundance, size structure and shell condition of adult females and males to fluctuate on a circa decadal time scale (Elner \& Beninger 1995, Sainte-Marie et al. 1996, Comeau et al. 1998). Moreover, owing to sexual dimorphism in size and age at adulthood, the fluctuations are asynchronous between the sexes and this causes large changes in the adult sex ratio and in the size differential among receptive females and males (Sainte-Marie et al. 1996).

To date, there is no evidence of size-assortative mating for snow crabs during the pubescent-primiparous or multiparous female breeding seasons. While it is generally accepted that male competition for multiparous females is intense (e.g. Conan \& Comeau 1986, Ennis et al. 1990, Elner \& Beninger 1992), it also has been asserted that males do not compete for pubescent-primiparous females and that pairing of males with these females occurs at random (Conan \& Comeau 1986, Moriyasu \& Conan 1988, Moriyasu \& Comeau 1996). The only field study of the mating of pubescent-primiparous females found no evidence of a size-assortative mating pattern (Sainte-Marie \& Hazel 1992). However, in the related Tanner crab Chionoecetes bairdi, Stevens et al. (1993) found a weak positive correlation $(r=0.22)$ between the body size of males and pubescent females in mating pairs.

The present study examines the composition of snow crab pairs in a population of the northwest Gulf of Saint Lawrence, eastern Canada, to determine the existence and causes of size-assortative mating during the pubescent-primiparous female breeding season. Field observations were conducted in 1991-92 and in 1995-96, during opposing phases of the population's recruitment cycle, when the abundance and characteristics of receptive females and males were very different.

\section{MATERIALS AND METHODS}

Study site and sampling. The study site was Baie Sainte-Marguerite, in the northwest Gulf of Saint Lawrence (ca $50^{\circ} 06^{\prime} \mathrm{N}, 66^{\circ} 35^{\prime} \mathrm{W}$ ), where the snow crab population has been monitored annually since 1988 (Sainte-Marie et al. 1996). Divers collected a total of 515 crab pairs from 19 to 27 March of 1991 and 1992, 21 to 26
March 1995, and 19 to 25 March 1996. These pairs were collected mostly from sand and occasionally rock bottoms at an average depth of 20 to $25 \mathrm{~m}$ (range 4 to $43 \mathrm{~m}$ ). Water temperature ranged from -1 to $-1.8^{\circ} \mathrm{C}$. During regular dives, all crab pairs were collected and placed individually into mesh bags on which the time and the depth of collection were recorded. For each dive we estimated a gross index of pair density, as the number of pairs collected per diver-hour. On 1 occasion in 1996 divers searched for males grasping a primiparous female and found 1 pair that was used for genetic analyses, but was excluded from assessments of mating associations.

In 1992, the ice-breaking ship MV 'Fogo Isle' was used to trawl the mating grounds concurrently with diver operations. Three $10 \mathrm{~min}$ trawl sets were performed with a $3 \mathrm{~m}$ beam trawl with $10 \mathrm{~mm}$ mesh in the codend. The trawl gave no information on mating associations, as paired females and males were separated in the net, but it provided a sample of the overall population of male snow crabs for comparison with diver collections (see Stevens et al. 1993).

Characterization of snow crabs. Diver-collected and trawled snow crabs were characterized by a variety of established criteria. Sex was determined according to the shape of the abdomen. We measured the carapace width (CW) of all crabs to the nearest $0.1 \mathrm{~mm}$, the width of the abdomen across the fifth sternite (AW) of females except in 1995, and the height of the right chela excluding spines $(\mathrm{CH})$ of males.

Shell condition was rated using the arbitrary scale of Sainte-Marie (1993) that reflects the time elapsed since the last molt: clean-soft (coded 1), clean-hard (2), intermediate (3), dirty-hard (4) and dirty-soft (5). In males, chela muscle weight increases from the clean-soft to the intermediate stage and remains high thereafter, while shell hardness increases through the clean-soft and clean-hard stages, peaks in the intermediate stage, and declines through the dirty-hard and dirtysoft stages owing to decalcification and necrosis (Dufour et al. 1997, Sainte-Marie unpubl. data). Thus, the intermediate stage combines maximum shell hardness and chela muscle weight (i.e. strength).

The number and position of missing limbs were recorded for all crabs. To reduce bias from possible trawl or diver damage to crabs, we recorded as missing only those limbs whose previous emplacement was marked by a dark or pale hard scar. Data on missing limbs were not used for soft postmolt crabs, because the distinction between recent and old limb losses could not easily be made.

Females were separated into various categories of maturity based on abdomen allometry, presence of eggs and shell condition. The term juvenile designates all females with a relatively narrow abdomen that are not committed to the terminal molt, i.e. immature and pre- 
pubescent females. Pubescent females also have a relatively narrow abdomen but are close to their terminal molt. Distinctions between juvenile and pubescent females can be made visually because the latter have mature bright orange ovaries that usually show through the first abdominal tergites, but we dissected all hard-shell females determined to be juvenile to confirm that ovaries were immature (Sainte-Marie \& Hazel 1992). Dissection also allowed us to determine if juvenile females were preparing to molt, as revealed by a new soft shell underlying the old shell. Adult females have undergone their terminal molt and are characterized by a broad abdomen with setose pleopods. The criteria used to determine the various types of adult females are from Alunno-Bruscia \& Sainte-Marie (1998): nulliparous females have a clean shell but have not yet extruded eggs, primiparous females have a clean shell and have extruded their first clutch of eggs, and multiparous females range in shell condition from intermediate to dirty-soft and may be carrying their second or subsequent egg clutch. In 1992, 15 randomly selected pubescent females from mating pairs were individually tagged and held in shipboard tanks with running seawater at ambient sea temperature until they molted. The delay between time of capture and molting was determined.

Males were categorized as adolescent or adult based on the relative size of their chelae, using the discriminant function in Sainte-Marie \& Hazel (1992). We recorded whether or not adolescent males were molting, as revealed by swelling of pericardial sacs, raising of the old carapace and presence of a new soft carapace beneath.

Genetic analyses. Five mating pairs of a male and a primiparous female collected in March 1996 were subjected to genetic analyses. Females in these pairs had a clean-soft shell and probably had molted to maturity no more than a day or two prior to collection. For each mating pair, female and male leg muscle, the whole egg clutch, and the contents of the left spermatheca were isolated and preserved in $100 \%$ ethanol. Samples were genotyped at microsatellite loci Cop 3-4 and Cop 24-3 by polymerase chain reaction following the methods of Urbani et al. (1998a,b).

Statistical analyses. A loading index for grasping males was calculated as the ratio of graspee CW over grasper CW. Statistics for this and other univariate data are the median or the mean and standard deviation. Depending on the type of variable and the distribution of data, routine parametric or nonparametric tests were used to compare univariate data. As expected, there were much sharper differences in crab features between the year pairs 1991-92 and 1995-96, than between years in a pair, so we analyzed and contrasted univariate data for year pairs.

In studies of size-assortative mating to date, female body size has been treated as the dependent variable and the relationship to male body size was described by Model I regression. However, this procedure is questionable since females may also be indirectly or directly implicated in mate choice (see below). Model II geometric mean regression (Ricker 1984) may be more appropriate because the ordinate and abscissa values are considered to be mutually variable and the resulting regression line is symmetrical regardless of the variable that is used on the ordinate.

Analysis of variance (ANOVA) was used to investigate the effects of year, male shell condition and number of missing limbs (factors) and of male $\mathrm{CW}$ and $\mathrm{CH}$ (covariates) on the size of paired pubescent females. Considering that females may also influence pair formation, we also investigated the effects of year, of female numberof-missing-limbs (factors) and of female CW and $\mathrm{AW}$ (covariates) on the size of paired males.

\section{RESULTS}

\section{Types of crab pairs and characteristics of graspees}

Paired crabs were dispersed or occurred in loose, meso-scale aggregations (10 to $100 \mathrm{~m}$ ). The abundance of paired crabs measured by diver collection rate was lower in 1991-92 (4.6 \pm 2.7 pairs diver-hour $\left.{ }^{-1}\right)$ than in $1995-96(7.6 \pm 4.1)(t$-test, $p<0.05)$. In each year, the $\mathrm{CW}$ of grasper or graspee was not correlated with depth or date of collection.

In the 4 years of this study $(1991,1992,1995$ and 1996), all graspers in the $515 \mathrm{crab}$ pairs collected by divers were male snow crabs. However, different kinds of graspees were represented in crab pairs and on this basis we recognized 8 different pair types (Table 1). In order of decreasing frequency, the graspee was either a pubescent female $(75.2 \%$ of all pairs), an adolescent male $(8.9 \%)$, a nulliparous female $(5.4 \%)$, a primiparous female $(4.5 \%)$, a juvenile female $(3.5 \%)$, an adult male $(2.1 \%)$ or a multiparous female $(0.2 \%)$ of snow crab. One mixed-species pair was found $(0.2 \%)$ in which a male snow crab was grasping a multiparous female Hyas araneus (Brachyura, Majidae). Most nulliparous and primiparous pairs were collected with the male and female in an indistinguishable pre- or post-copulatory embrace, although rarely some were sampled as they copulated. Only those pairs in which a male mated a pubescent, nulliparous, primiparous or multiparous female snow crab could produce a clutch of viable eggs, so we designate these types collectively as 'potentially fecund' pairs. The remaining pair types are designated collectively as 'nonfecund' pairs. The overall proportion of potentially fecund pairs to all crab pairs was $85.1 \%$.

There was a coherent variation of the $\mathrm{CW}$ of paired premolt (pubescent) and postmolt (nulliparous and 
Table 1. Chionoecetes opilio. Types of crab pairs based on the identity of crab held by male snow crabs collected by divers in Baie SainteMarguerite during March 1991, 1992, 1995 and 1996. The relative abundance of pair types is expressed as a percentage of total number of pairs. The 3 numbers in parentheses for $C$. opilio graspees in nonfecund pairs represent the actual number of individuals in the premolt, clean-soft (postmolt) and hard-shell intermolt or terminal molt condition

\begin{tabular}{|lcc|}
\hline Pair type & $1991-92$ & $1995-96$ \\
\hline Potentially fecund & & \\
C. opilio pubescent female & 81.0 & 68.6 \\
C. opilio nulliparous female & 3.7 & 7.4 \\
C. opilio primiparous female & 4.4 & 4.6 \\
C. opilio multiparous female & 0.4 & 0.0 \\
Nonfecund & & \\
C. opilio juvenile female & $3.7(4-5-1)$ & $3.3(4-4-0)$ \\
C. opilio adolescent male & $4.4(3-5-4)$ & $14.1(3-20-11)$ \\
C. opilio adult male & $2.2(0-1-5)$ & $2.1(0-5-0)$ \\
Hyas araneus multiparous female & 0.4 & 0 \\
Total number of pairs & 273 & 242 \\
& & \\
\hline
\end{tabular}

nulliparous pairs than in primiparous and nonfecund pairs. Males in pubescent pairs were significantly larger than grasping males in primiparous and in nonfecund pairs in 1991-92 and than grasping males in nonfecund pairs in 1995-96 (Fig. 2). Note that the size of males was more variable in 1995-96 than in 1991-92 for any given pair type. In potentially fecund pairs, the $\mathrm{CW}$ of males ranged from 52.4 to $109.3 \mathrm{~mm}$ in $1991-92$ and from 47.9 to $126.8 \mathrm{~mm}$ in $1995-96$ (Fig. 2). Grasping males were significantly larger in 1995-96 than in 1991-92 in pubescent pairs (Mann-Whitney test, $p<0.001$ ) and in nonfecund pairs $(p<0.05)$, but not in nulliparous and primiparous pairs. Analysis of $\mathrm{CH}$ for grasping males gave similar results to the above.

The proportion of grasping males with an intermediate shell was greater in pubescent and nulliparous pairs than in primiparous and

primiparous) female snow crabs across year pairs, the females being larger in 1991-92 than in 1995-96 (Table 2). Pubescent females were missing more limbs in 1995-96 (median $=1$ ) than in 1991-92 (median $=0$, Mann-Whitney test, $p<0.01$ ). The maximum number of missing limbs per pubescent female was 5 in each year except in 1995, when the maximum was 7 . In 1992, the minimum, median and maximum delays between time of collection and the molt of paired pubescent females were 1, 6 and $13 \mathrm{~d}$, respectively.

Examination of the molt status of snow crab graspees in nonfecund pairs over the study period (Table 1) revealed a high percentage of premolt and postmolt individuals for both juvenile females (94.4\% of 18 ) and adolescent males (67.4\% of 46 ). Moreover, the proportion of adolescent male graspees that were premolt may be underestimated, as these crabs were not dissected, in contrast to the juvenile females. All but 1 of the adult male graspees had a hard shell in 1991-92 and all had a clean-soft shell in 1995-96. nonfecund pairs in 1991-92 and in 1995-96 (Fig. 2). In the last 2 pair types, grasping males predominantly had a dirty-hard shell. Small proportions of grasping males with a dirty-soft shell occurred in potentially fecund and nonfecund pairs (Fig. 2). One male with a cleanhard shell was found grasping a pubescent female in 1991-92 and 3 were found in pubescent and nulliparous pairs in 1995-96 (Fig. 2). Males with a clean-soft shell occurred in crab pairs only in 1995-96, when they accounted for $14.9 \%$ of graspers in nonfecund pairs.

The proportion of grasping males missing $>1$ limb was always higher in primiparous and nonfecund pairs than in pubescent and nulliparous pairs (Fig. 2). However, differences among pair types in the proportions of grasping males missing 0,1 or $>1$ limb were significant only in 1991-92.

The median loading index was significantly less for males grasping pubescent females than for males grasping primiparous females in 1991-92 and in 1995-96 (Fig. 2). The loading index was significantly

\section{Characteristics of graspers in relation to pair type}

Overall, the proportion of graspers that were adult males was $96.1 \%$ in pubescent pairs, $92.9 \%$ in nulliparous pairs, $87.0 \%$ in primiparous pairs and $83.8 \%$ in nonfecund pairs ( $G$-test of independence with William's correction, $\mathrm{p}<0.001$ ). The remaining graspers were adolescent males.

In each year, the median CW of grasping males was larger in pubescent and
Table 2. Chionoecetes opilio. Mean and standard deviation of carapace width ( $\mathrm{CW} \mathrm{mm}$ ) of paired pubescent, nulliparous and primiparous females, and of juvenile females, adolescent males or adult males in nonfecund pairs collected by divers in Baie Sainte-Marguerite during March 1991, 1992, 1995 and 1996. The Mann-Whitney test was used to check for differences in CW between year pairs

\begin{tabular}{|c|c|c|c|}
\hline Graspee identity & $1991-92$ & $1995-96$ & Test \\
\hline Pubescent female & $51.4 \pm 4.4$ & $44.4 \pm 5.2$ & $\mathrm{p}<0.001$ \\
\hline Nulliparous and primiparous females & $61.6 \pm 4.8$ & $51.1 \pm 5.8$ & $\mathrm{p}<0.001$ \\
\hline Graspees in nonfecund pairs & $48.0 \pm 13.0^{a}$ & $47.0 \pm 12.0$ & $p>0.05$ \\
\hline
\end{tabular}



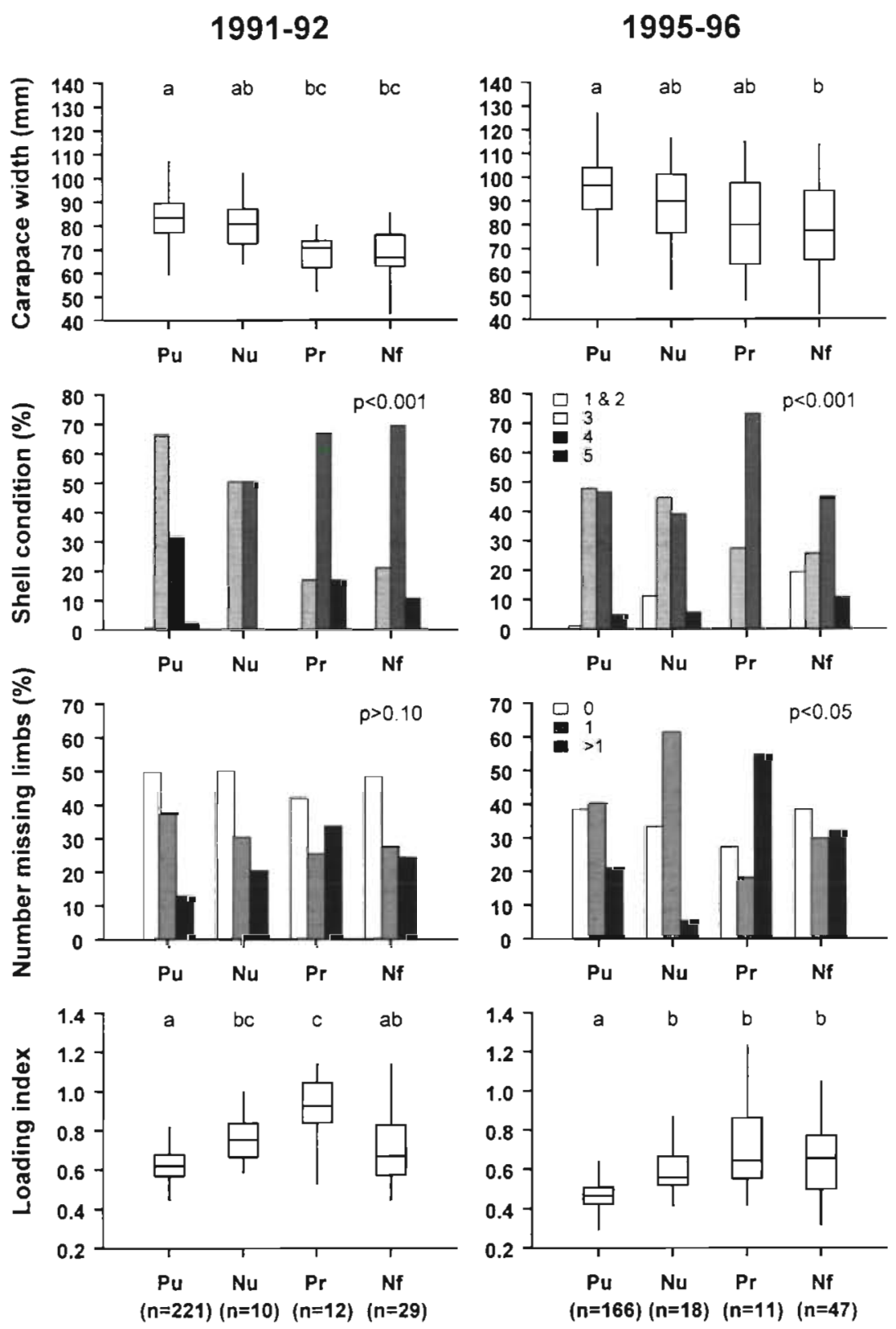

Type of mating pair

Fig. 2. Chionoecetes opilio. Box plots of carapace width and loading index, and bar charts of proportions of shell condition and number of missing limbs, for grasping male snow crabs in pubescent $(\mathrm{Pu})$, nulliparous (Nu), primiparous ( $\mathrm{Pr}$ ) and nonfecund (Nf) pairs collected by divers in Baie Sainte-Marguerite during March 1991, 1992, 1995 and 1996. The loading index is the ratio of graspee to grasper carapace widths. Box plots show the median value and lower and upper quartile, with whiskers extending to minimum and maximum values in the sample. Heterogeneity in carapace width and loading index across pair types was significant in 1991-92 and 1995-96 (Kruskal-Wallis test, $\mathrm{p}<0.001$ ), so Dunn's a posteriori test was used to contrast pair types (letters above bars designate pair types with similar characteristics). Shell conditions are rated 1 (clean-soft), 2 (clean-hard), 3 (intermediate), 4 (dirty-hard) and 5 (dirty-soft). Probabilities in bar charts are the results of a $G$-test of independence on proportion of males with intermediate shell relative to males with all other shell conditions and on proportion of males missing 0,1 or $\geq 2$ limbs greater in 1991-92 than in 1995-96 for males grasping pubescent (MannWhitney test, $\mathrm{p}<0.001$ ), nulliparous $(\mathrm{p}<0.01)$ and primiparous $(\mathrm{p}<0.05)$ females, but not for grasping males in nonfecund pairs.

A matrix of Spearman rank correlations between shell condition, number of missing limbs, CW and CH of grasping males in all crab pairs was constructed for 1991-92 and 1995-96. Apart from the obvious relationship between $\mathrm{CW}$ and $\mathrm{CH}$, the only significant correlations were between shell condition and size in 1991-92 (CW: $\mathrm{r}_{\mathrm{s}}=-0.36, \mathrm{p}<0.001 ; \mathrm{CH}: \mathrm{r}_{\mathrm{s}}=-0.33$, $\mathrm{p}<0.001$ ) and between number of missing limbs and size in 1995-96 (CW: $\mathrm{r}_{\mathrm{s}}=-0.22, \mathrm{p}<0.001 ; \mathrm{CH}: \mathrm{r}_{\mathrm{s}}=-0.21$, $\mathrm{p}=0.001)$.

\section{Comparison of trawled and paired males}

A matrix of Spearman rank correlations for adult males in trawl samples taken on the mating grounds concurrently with diver sampling in 1992 showed that the size of males was negatively correlated with shell condition $\left(\mathrm{CW}: \mathrm{I}_{\mathrm{s}}=-0.41, \mathrm{p}<0.001 ; \mathrm{CH}\right.$ : $\left.\mathrm{r}_{\mathrm{s}}=-0.46, \mathrm{p}<0.001\right)$ and number of missing limbs (CW: $\mathrm{r}_{\mathrm{s}}=-0.33, \mathrm{p}<0.01$; $\left.\mathrm{CH}: \mathrm{r}_{\mathrm{s}}=-0.36, \mathrm{p}<0.001\right)$. There was also a weak positive correlation between shell condition and number of missing limbs $\left(r_{\mathrm{s}}=0.22, \mathrm{p}=0.047\right)$.

The comparison of paired males with males in concurrent trawl samples in 1992 is limited to adults because there were few paired adolescents. Adult males in the predominant pubescent pairs were significantly larger than trawled adult males (Fig. 3). The proportion of adult males with a dirty-hard shell was equal in pubescent pairs and in trawl samples, while adult males with an intermediate shell and a dirty-soft shell were, respectively, about 5 times more frequent and 15 times less frequent in pubescent pairs than in trawl samples (Fig. 3). Adult males with no or 1 missing limb occurred more frequently in pubescent pairs than in trawl 
samples by a factor of about 2 and 1.5, respectively, and conversely adult males missing more than 1 limb were sharply under-represented in pubescent pairs compared to trawl samples (Fig. 3). The missing limbs were usually walking legs, and there was no difference ( $G$-test of independence with Williams correction, $p>0.1$ ) in the proportion of adult males lacking 1 chela between pubescent pairs (12.4\%) and trawl samples (19.8\%).

Adult males in nonfecund pairs and in trawl samples were represented by individuals of the same median size, with an equally low proportion of intermediate shell condition and a similarly high proportion missing more than 1 limb (Fig. 3). In 1992, divers collected only 1 nulliparous pair and the number of primiparous pairs was small. Notwithstanding, the median CW of adult males grasping primiparous females was not significantly different from that of trawled adult males (Fig. 3). We did not, however, test for differences in shell condition and number of missing limbs between adult males in primiparous pairs and in trawl samples given the requirements of tests of independence.

\section{Size-assortative mating}

Focusing on the predominant pubescent pairs, we first tested by ANOVA for effects of year and male traits on female CW. Only year of observation $(\mathrm{p}<0.001)$ and the covariate male $\mathrm{CH}(\mathrm{p}<0.001)$ explained a significant amount of the variation in female CW, while male CW explained none. Regression analyses indicated that male $\mathrm{CH}$ explained a greater proportion of the variation in female body size than male $C W$ in 3 out of 4 years, and the relationship between male CW and female CW was not significant in 1991 (see CW data graphed in Sainte-Marie \& Hazel 1992). Nonetheless, the total amount of variation in female CW explained by male $\mathrm{CH}$ was small $\left(\mathrm{r}^{2}=3.8\right.$ to $11.2 \%$, depending on the year). The slope of the Model II regression of female CW on male $\mathrm{CH}$ by year (Fig. 4) did not differ significantly from 1 except in 1992, when it was substantially higher ( $t$-test, $p<0.05$ ). Note that the elevation of the regression lines changed among years, reflecting the changing size structures of females and males, a fact most obvious when year pairs are compared (Fig. 4).

We then tested by ANOVA for effects of year of observation and pubescent female traits on male CW or male $\mathrm{CH}$. As could be expected from the abovementioned results, female traits explained a greater proportion of variation of male $\mathrm{CH}$ than of male $\mathrm{CW}$; therefore, we present only results of the former analysis. Since female AW data were not available for 1995 and since AW varied independently of number of missing limbs in other years, we performed 2 ANOVAs on male $\mathrm{CH}$ to verify the effects of $\mathrm{AW}$ and the number of missing limbs of females separately while maximizing the number of data. In the first ANOVA (1995 excluded), a significant proportion of variation in male $\mathrm{CH}$ was explained by the factor year $(\mathrm{p}<0.001)$ and by the covariates female $\mathrm{CW}(\mathrm{p}<0.001)$ and $\mathrm{AW}$ $(p=0.01)$. In each year for which data were available, partial correlation analysis gave a positive coefficient between male $\mathrm{CH}$ and female $\mathrm{CW}$ ( $\mathrm{r}=0.21$ to 0.25 , depending on the year) and a negative coefficient
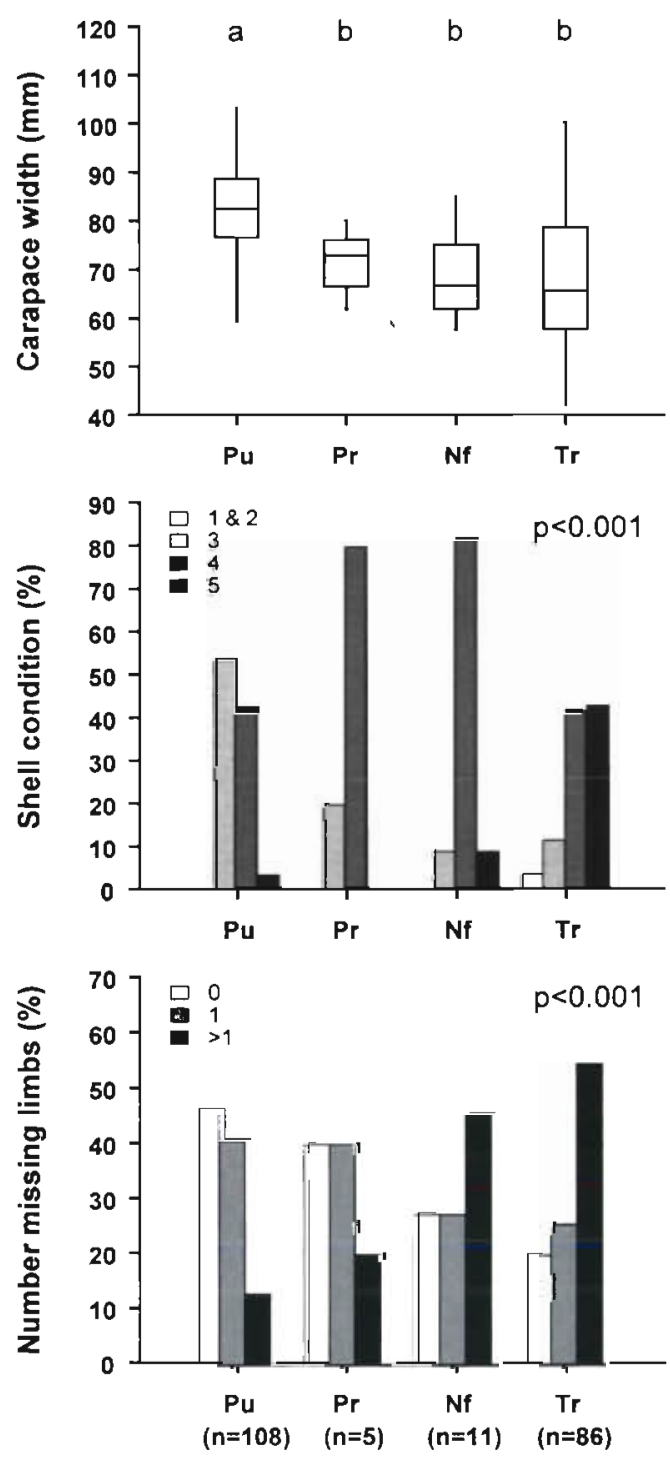

Fig. 3. Chionoecetes opilio. Box plots of carapace width and bar charts of proportions of shell condition and number of missing limbs, for grasping adult male snow crabs in pubescent $(\mathrm{Pu})$, primiparous (Pr) and nonfecund (Nf) pairs collected by divers, and for adult male $C$. opilio collected by trawl ( $\mathrm{Tr}$ ) on the same grounds of Baie Sainte-Marguerite during March 1992. Refer to Fig. 2 legend for description of traits and tests. Primiparous pairs were excluded from the $G$-test of independence on shell condition and number of missing limbs due to the small sample size 


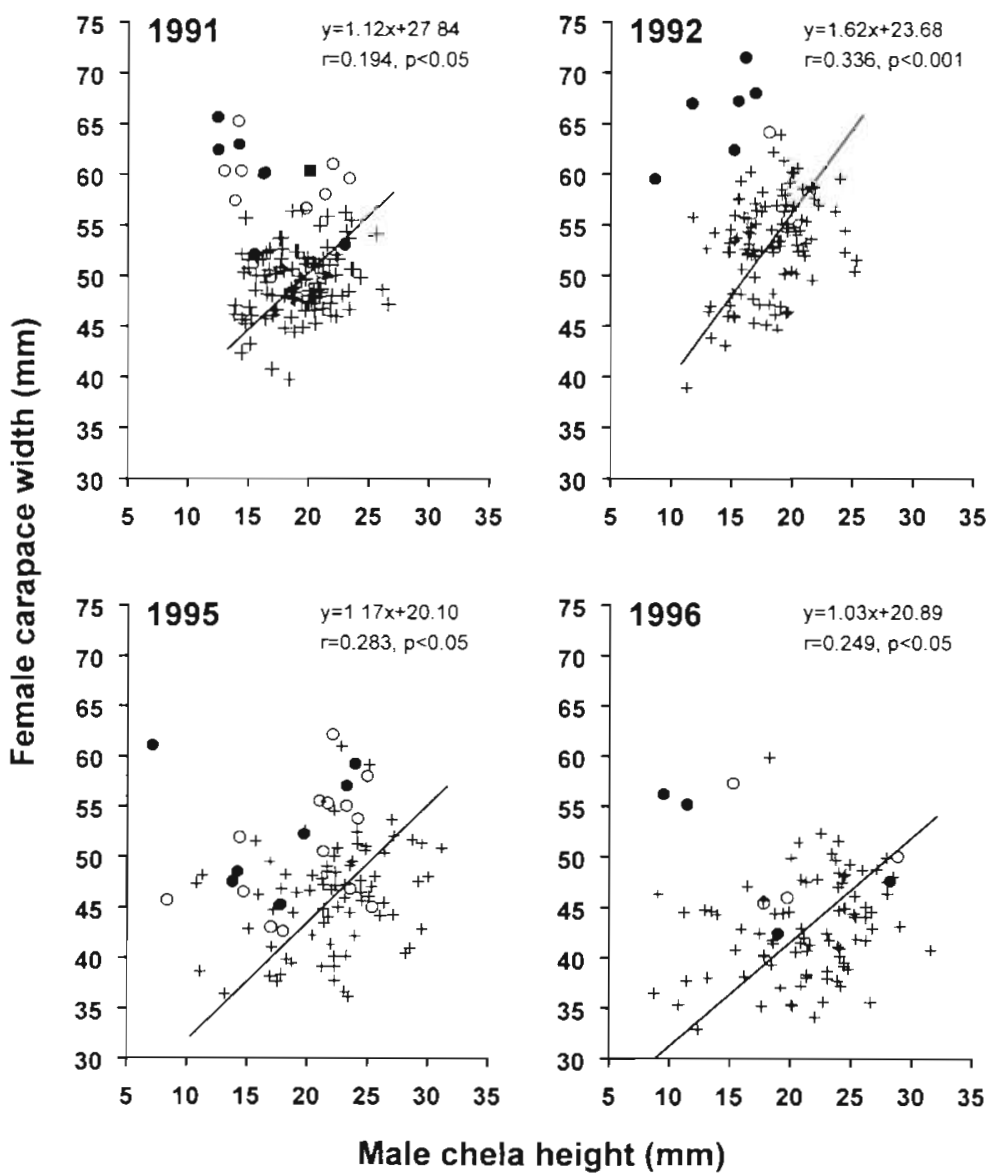

Fig. 4. Chionoecetes opilio. Scatterplots of right chela height for males and of carapace width for pubescent $(+)$, nulliparous $(0)$, primiparous $(\bullet)$ or multiparous (a) females in pairs collected by divers in Baie SainteMarguerite during March 1991, 1992, 1995 and 1996. The equation of the Model Il regression of pubescent female carapace width on male chela height (solid line and equation), corresponding product-moment correlation coefficient and probability level are given in each graph

10.8 to $21.1 \%$, depending on the year. This was at least twice the amount of variation explained by female CW alone.

There was no correlation between the CW of nulliparous or primiparous females and the $\mathrm{CH}$ (or $\mathrm{CW}$ ) of males in pairs, albeit data were few in each year (Fig. 4). Similarly, there was no relationship between male $\mathrm{CH}$ or $\mathrm{CW}$ and graspee $\mathrm{CW}$ in nonfecund pairs (data not shown).

\section{Genetic evidence for multiple mating of females}

The results of genetic typing of the 5 primiparous pairs collected in 1996 were coherent for the 2 microsatellite loci examined. The females had each been inseminated by 2 to 6 males (Table 3). However, none of the grasping males associated with a primiparous female had sired her embryos, and only in Pair 1 had the grasping male already inseminated the female. Interestingly, this occurred in the primiparous pair with the smallest male and highest loading index (1.17). It is noteworthy that in Pairs 2, 3 and 4 there was apparently no paternal sperm left over in the spermatheca.

In 1996, there was a positive but statistically nonsignificant correlation between the spermathecal load and the number of male genotypes represented in the spermatheca $\left(\mathrm{r}_{\mathrm{s}}=0.95, \mathrm{p}=0.058\right)$. If 1996 data are pooled with 1995 data from the same site (Urbani et al. 1998a), the correlation between the spermathecal load and the number of male genotypes is significant $\left(r_{s}=0.68, n=12, p<0.05\right)$.

between male $\mathrm{CH}$ and female AW ( $\mathrm{r}=-0.12$ to -0.19$)$ This implies that larger females were paired with males with larger chelae for a constant female AW, and that females with relatively narrower abdomens were paired with males with larger chelae than females with relatively broader abdomens. In the second ANOVA (1995 included), a significant proportion of variation in male $\mathrm{CH}$ was explained by the factors year $(\mathrm{p}<0.001)$ and female number-of-missing-limbs $(p<0.05)$ and by the covariate female CW $(p<0.001)$. Examination of male $\mathrm{CH}$ adjusted to constant female $\mathrm{CW}$ revealed a declining $\mathrm{CH}$ trend with increasing female number-ofmissing-limbs $\left(r_{\varsigma}=-0.93, p<0.05\right)$. For a constant $C W$, females missing more limbs were therefore paired with males with smaller chelae. The amount of variation in male $\mathrm{CH}$ that could be explained by female CW, AW and number of missing limbs together ranged from
These observations indicate a functional relationship between the number of matings a female is involved in and the size of her ejaculate (sperm) stores.

\section{DISCUSSION}

\section{Two assortative mating patterns}

Several types of snow crab pairs occurred on the Baie Sainte-Marguerite grounds during the pubescent-primiparous breeding season (Table 1). Excluding the multiparous pair, the pairs can be ranked by increasing reproductive value of the graspee to the grasper: (1) In nonfecund pairs, the graspee offered the male no fecundity benefit. (2) In primiparous pairs, the female had already oviposited and therefore could 
provide no immediate fecundity benefit to the male. Indeed, postcopulatory guarding by males typically does not extend past oviposition (Sainte-Marie et al. 1997), and genetic typing of 5 primiparous pairs in the present study accordingly indicated that the male grasping a primiparous female had not sired her embryos (Table 3). Thus, this male was not protecting his reproductive investment. However, if the grasping male inseminated the primiparous female his sperm might be used for fertilization of the next egg clutch, so the female may offer a long-term fecundity benefit. In the case of dirty-soft males, which are senescent and have a very short life expectancy, the primiparous female may become the repository of sperm that are destined to die if not passed along and the uncertain reward of paternity can only be posthumous. (3) In pubescent pairs, the female was still virgin and was of high value to the male, although the time to molting and oviposition could be of variable length. (4) In mulliparous pairs, the female was close to oviposition and was also of high value to the male, especially if he had already inseminated her and was guarding her until oviposition to ensure his paternity.

The pairing of snow crabs during the pubescentprimiparous female mating season did not occur at random: 2 distinct assortative mating patterns were apparent. First, quality-based pairing occurred at the population level, with high-value pubescent and nulliparous females associating with males that were larger, had a harder shell and were missing fewer limbs than males in primiparous or nonfecund pairs (Fig. 2). Second, in each year there was some degree of size-assortative mating by female $\mathrm{CW}$ and male $\mathrm{CH}$ in pubescent pairs (Fig. 4).

Table 3. Chionoecetes opilio. Genetic analysis of 5 primiparous pairs collected by divers in Baie Sainte-Marguerite during March 1996. Male and female carapace width ( $\mathrm{CW}$, in $\mathrm{mm}$ ), number of non-maternal alleles in left spermatheca for microsatellite loci Cop3-4 and Cop24-3, least number of mates based on spermathecal contents (number in parentheses includes father when his genotype was not found in spermatheca), presence of father's and of grasper's sperm in the spermatheca, and ejaculate load ( $g$ formalin-preserved equivalent weight) for the spermatheca are given for each pair. Least number of mates calculated as the maximum number of nonmaternal alleles in the spermatheca divided by 2 and rounded to the nearest higher integer when the quotient is uneven (Urbani et al. 1998a). The fifth pair was collected by divers during a directed survey and is not tallied in other tables

\begin{tabular}{lrcccccccc|}
\hline \multirow{2}{*}{$\begin{array}{l}\text { Pair } \\
\text { identity }\end{array}$} & Male Female & CW & Alleles & \multicolumn{7}{c}{ Alleles } & \multicolumn{3}{c}{ No. } & Father & Grasper Ejaculate \\
& & & Cop3-4 & Cop24-3 & of mates & sperm & sperm & load \\
\hline 1 & 48.2 & 56.2 & 10 & 9 & 5 & Yes & Yes & 0.199 \\
2 & 61.6 & 55.2 & 2 & 2 & $1(2)$ & No & No & 0.068 \\
3 & 114.6 & 47.6 & 2 & 1 & $1(2)$ & No & No & 0.036 \\
4 & 84.4 & 42.4 & 9 & 7 & $5(6)$ & No & No & 0.116 \\
5 & 82.6 & 55.1 & 4 & 4 & 2 & Yes & No & 0.083 \\
\hline
\end{tabular}

\section{Causes of assortative mating}

The 2 assortative mating patterns did not result from tial or temporal covariation in the different types or of individuals available for mating. In each year, and there was no evidence of heterogeneity in the type or size of mates by depth. Moreover, in each year paired crabs were collected over only 6 to 9 successive days and the type and size of mates did not change win collection periods

The 2 assortative mating patterns also did not appea from loading constraints on the males. Indeed pubescent pairs, there was considerable interannual variation in the elevation of regression lines of female $\mathrm{CW}$ on male $\mathrm{CH}$ (Fig. 4). This suggests that there was no lower or upper physical limit to the size of female that could be carried by a male, at least for the size combinations of receptive females and males reprecent females and of adult males resulting from recruitment troughs and waves (Sainte-Marie et al. 1996). It also is apparent that most males can effectively mate with a female irrespective of the size differential in a pair. This is supported by the very large size range for males in potentially fecund pairs $(47.9$ to $126.8 \mathrm{~mm}$ CW), by the fact that a very small male inseminated a larger primiparous female (Table 3 ) and by the fact that laboratory studies found no sizedifferential copulatory incompatibility between the sexes (Sainte-Marie \& Lovrich 1994, Sainte-Marie et al. 1997).

Sexual competition and mate choice in the context of prolonged female attractiveness to males are, thus, the most likely causes of assortative mating patterns in snow crabs. Competitive ability of Chionoecetes spp. males depends on shell condition, number of missing limbs and chela/body size. It is commonly accepted that postmolt males do not breed (Conan \& Comeau 1986. Stevens et al. 1993, Paul et al. 1995), but a small number exhibited grasping behavior with juvenile females and other males in the present study. Males with a clean-hard shell will mate in a noncompetitive laboratory situation (Sainte-Marie pers. obs.), and 
a few paired with pubescent and nulliparous females in the field (Fig. 2). Although similar numbers of males with an intermediate shell or with a dirty-hard shell mated with the high-value pubescent and nulliparous females (Fig. 2), the comparison of shell condition of adult males represented in pubescent pairs and in trawl samples (Fig. 3) strongly suggests that males with an intermediate shell enjoyed the highest reproductive success. The progression of male reproductive success from the cleansoft to the intermediate shell condition coincides with shell hardening and increasing chela strength, which confer greater competitive ability and reduce the risks of injury during altercations with other males (e.g. Knuckey 1996, Reid et al. 1997). In fact, the emergence and intensification of reproductive behavior in males may be linked to a gradual postmolt increase in the concentration of sex hormones (Laufer et al. 1996). At the end of the spectrum of shell condition for snow crabs, dirty-soft males occurred in snow crab pubescent pairs in a much smaller proportion than would be expected if pairing occurred independently of shell condition (Fig. 3). These males are senescing and although they are capable of grasping and inseminating pubescent-primiparous females, they are not very mobile and may even be displaced by smaller males with an intermediate shell (Sainte-Marie pers. obs.).

Male snow crabs missing more than 1 walking leg were reproductively less successful than males missing none. Male Chionoecetes spp. search for females and when they possess one they may evade the challenge of another male by fleeing (Paul \& Paul 1996. SainteMarie pers. obs.). The efficacy of both activities would undoubtedly depend on all or most walking legs being intact. Moreover, in snow crabs and other majids, male posturing to intimidate rivals and/or to protect a mate from takeover implicates a 'high-on-legs' stance (Hazlett 1972, Donaldson \& Adams 1989) which may be facilitated by long and intact walking legs (Stevens et al. 1993).

Large males were much more likely than small males to be associated with high-value pubescent females, and in this pair type the larger males also appropriated the larger and potentially more fecund females. However, in contrast to a previous inference for snow crabs (Conan \& Comeau 1986), the present results demonstrate that large chela size is a more decisive trait than large body size for male mating success (see also Sainte-Marie et al. 1997). This finding is consistent with observations on other brachyuran crabs showing that chela size is a more appropriate indicator than body size of male dominance, and a better gauge of the potential outcome of agonistic sexual interactions (Lee \& Seed 1992).

Male inferiority by size may be compounded by other disadvantageous features, as in 1992 when trawl samples showed that small adult males had an older shell and were missing more limbs than large adult males. This situation reflected the receding recruitment and aging of small adult males and the surge in recruitment of large adult males associated with the passage of a recruitment wave (Sainte-Marie et al. 1996). Reciprocally, at other times the competitive inferiority of small adult males may to some degree be offset by a better shell condition or fewer missing limbs than large males. In 1995-96, a new recruitment wave unfurled that brought about a surge in the number of small adult males while the abundance of large adult males receded and their condition deteriorated (Dufour \& Sainte-Marie 1998). However, it is likely that size is the most important trait for reproductive success of males that are neither recently molted nor senescent, or that are not missing too many limbs, in snow crabs as in other crab species (e.g. Smith 1992).

The conclusion that sexual competition is an important factor determining the 2 assortative mating patterns is supported by several lines of evidence: (1) In 1992, the concurrent trawl and diver sampling revealed that adult males that paired with high-value pubescent females were larger, superior in shell condition and were missing fewer limbs than adult males in the overall population (Fig. 3). (2) The size range of males in fecund pairs was much broader in 1995-96 than in 1991-92, and the density of crab pairs (present study) and the abundance of primiparous females were also greater in 1995-96 than in 1991-92 (Dufour \& Sainte-Marie 1998), suggesting that relaxed male competition afforded some of the smaller males with an intermediate shell and few missing limbs the opportunity to mate with high-value females, in spite of the presence of very large males. The smaller size of females in 1995-96 compared to 1991-92 (Table 2) may also have influenced the mating success of small or otherwise inferior males, if there exists some form of female choice (see below). Evidence that male sexual competition was relaxed in 1995-96 also comes from the lower ratio of pubescent to nulliparous and primiparous females (Table 1). This suggests that the duration of precopulatory guarding by males was reduced (see Reid et al. 1994), as predicted under circumstances of greater female availability (Grafen \& Ridley 1983). (3) Finally, a laboratory study has shown that males fight for pubescent and nulliparous females and that there is a size advantage in sexual competition (Sainte-Marie et al. 1997); this is also suggested by casual observations of interactions between males and females in the field (Sainte-Marie \& Hazel 1992).

Strong evidence for mate choice was seen in the size-assortative mating pattern of pubescent females, which was based on multiple criteria probably reflecting the female's potential for surviving and producing many eggs. Indeed, we found that female body size was positively correlated with male $\mathrm{CH}$, while the 
number of missing limbs and the relative width of the abdomen of females were negatively correlated with male $\mathrm{CH}$. In a species in which female maturity is associated with a terminal molt, the number of limbs that a pubescent female is missing may have a direct impact on her life expectancy and on her lifetime reproductive output. A female's mobility and capability to forage and escape predators, and therefore the number and size of clutches she will carry in the course of a lifetime, may be directly linked to the number of limbs she is missing (for a general discussion, see Juanes \& Smith 1995). The implications for female survival and fecundity of a relatively broad abdomen are not so obvious, but one possibility can be derived from the analysis of molt increment data in Alunno-Bruscia \& Sainte-Marie (1998). The relationship of post- to pre-terminal molt AW to CW ratio for females was not flat $(\mathrm{I}=0.33$, $p<0.001$ ), indicating that initial differences in this ratio among pubescent females are amplified through the terminal molt. There may be an optimal AW to CW ratio for the abdomen to function effectively as a brood chamber while not hindering mobility (Hartnoll 1982), and pubescent female snow crabs with higher AW to $\mathrm{CW}$ ratios would after terminal molt fall above the mean value of 0.68 reported for adult females (AlunnoBruscia \& Sainte-Marie 1998). Male Chionoecetes spp. may assess the female's body size on the basis of weight, and her maturity, number of missing limbs and abdomen width through a variety of elaborate stroking and palpating behaviors that are performed during the initial stages of mating (see Donaldson \& Adams 1989).

Other factors could contribute to explain some of the variation in the size-assortative mating pattern that is not accounted for. In other brachyuran species and conceivably in snow crabs, pair formation may be influenced by female proximity to maturity molt, those females being closest to molt being more likely to pair or preferred by males (e.g. Haddon 1994, Jivoff \& Hines 1998). There also may be some measure of indirect or direct female choice implicated in pair formation, for example resistance to mate that would favor males with larger body size and/or chelae (Christy 1987, Donaldson \& Adams 1989, Smith 1992, Stevens et al. 1993, Claxton et al. 1994, Orensanz et al. 1995). During the first breeding season of female snow crabs, it is likely that female attempts to resist mating and associated mate choice are restricted to the pubescent phase, given the risks of injury that such a behavior would pose to soft nulliparous or primiparous females.

However, much of the variability in the size-assortative mating pattern may be inherent to the process of mate choice. In species combining female-centered competition and free search patterns by males (Christy 1987), such as appears to be the case in snow crabs, the process of assortative mating may be a lottery in which mobile males attempt to upgrade their mate in favor of one offering better or more immediate fecundity benefits. This may involve rejecting a mate in favor of an unattended female or a female stolen from a rival male, as observed in the field (Hooper 1986) and laboratory (Sainte-Marie unpubl. data). Such a process implicates some degree of chance and would necessarily result in an imperfect assortment of mates by size

\section{Significance of mating associations}

The occurrence of nonfecund pairs was common in our diving surveys and appears to be unique to the pubescent-primiparous mating season of snow crabs. Nonfecund pairs have never been seen in nature during the multiparous mating season (M. Comeau, Department of Fisheries and Oceans, Maritimes Region, Moncton, New Brunswick, Canada, pers. comm.) which occurs later in the year, after the species' main annual molting period (Lovrich et al. 1995, Bouchard et al. 1996). Graspees in nonfecund pairs were frequently pre- and post-molt crabs (Table 1) and crustecdysone and/or its metabolites may be an olfactive cue for pair formation (Bouchard et al. 1996, Pelletier et al. 1998). Thus, a reasonable explanation for the existence of nonfecund pairs during the pubescent-primiparous mating season, and lack thereof during the multiparous mating season, is that they represent cases of mistaken identity. Similar arguments have been put forth to explain homosexual pairs in the box crab Calappa lophos (Kazmi \& Tirmizi 1987) and in the paddle crab Ovalipes catharus (Haddon 1994). Alternatively, Moriyasu \& Comeau (1996) suggested that homosexual pairing might reflect the establishment of dominance hierarchies prior to mating. However, this seems unlikely given the small size of male graspers and the fact that most male graspees had a clean-soft shell (present study) and would avoid hard-shell males instead of challenging them (Conan \& Comeau 1986).

Multiple mating during the first breeding season of female snow crabs appears to occur routinely and may be beneficial to the females in a variety of ways. In the absence of postcopulatory guarding until the female's shell hardens and she ceases to be attractive to males, multiple mating may simply be a form of 'convenience polyandry' whereby the risks of injury arising from male harassment are diminished (e.g. as seen in some insects, Rowe 1992). However, the strategy of multiple mating may be more elaborate, as the resulting larger and genetically more diversified sperm stores may ensure high fertilization rates for future egg clutches, even if the female never re-mates (Urbani et al. 1998a). Furthermore, since males do not compete for, and only briefly mate, postmolt primiparous females (SainteMarie et al. 1997), the latter may acquire additional 
sperm at less risk than if they re-mate later in life under circumstances of possibly more intense male competition.

The characteristics of mates and the mating patterns recorded in the present study are not necessarily representative of the complete duration of the pubescentprimiparous female mating season. Indeed, we sampled mating pairs only near the end of the pubescentprimiparous female mating season. It is conceivable that mating interactions change over a breeding season, as seen for example in the isopod Asellus aquaticus (Ridley \& Thompson 1979) and in the hermit crab Pagurus middendorffii (Wada et al. 1996). The latter species exhibits temporal covariation in the size of females and males available for mating over 1 breeding season, leading to changes in the mating patterns during the breeding season. For snow crabs in Baie Sainte-Marguerite, there is evidence that adult males represented on the pubescent-primiparous female mating grounds were smaller in December 1991 than in March 1992 (see Lovrich et al. 1995). This could have afforded large adolescent males an opportunity for mating just prior to their molting season, when they were hard-shell, as discussed by Sainte-Marie et al. (1995).

The present study indicates that the mating system of snow crabs offers considerable flexibility for female and male interactions. As hypothesized by Elner \& Beninger (1995), snow crabs are not restricted to a rigid mating pattern and breeding opportunities exist for inferior males within and across years due to changing levels of sexual competition. The snow crab mating system can be envisioned as a complex dichotomy of mating opportunities of different value to the male: multiparous (relatively high fecundity, if not senescent) versus pubescent-nulliparous (relatively low fecundity) females, large (high fecundity) versus small (low fecundity) females, and pubescent (virgin) versus primiparous (previously inseminated) females. These dynamic features of the snow crab mating system may explain why the male has evolutionarily maintained a broad size range for terminal molt and different size-dependent mating strategies.

Acknowledgements. This work was conducted in dangerous and trying conditions. It would not have been possible without the help and diving skills of L. Bourdages, G. Fournier, Y Gagnon, J. Easton, S. Raymond, P. Bernier, R. Larocque and C. Poirier. We are particularly grateful to P. Goudreau who endured extreme conditions during long hours of surface support. We thank R. Dufour, J. Freire, H. Guderley, P. R. Jivoff, J. M. (Lobo) Orensanz, A. Rondeau and the anonymous reviewers for comments on an early draft of the manuscript. This study was supported by Quebec Federal Fisheries Development Programme and Department of Fisheries and Oceans funds to B.S.-M. and Natural Sciences and Engineering Research Council funds to U.K.

\section{LITERATURE CITED}

Alunno-Bruscia M, Sainte-Marie B (1998) Abdomen allometry, ovary development, and growth of female snow crab Chionoecetes opilio in the Gulf of Saint Lawrence (Brachyura, Majidae). Can J Fish Aquat Sci 55:459-477

Bouchard S, Sainte-Marie B, McNeil JN (1996) Indirect evidence indicates female semiochemicals release male precopulatory behaviour in the snow crab, Chionoecetes opilio (Brachyura: Majidae). Chemoecology 7:39-44

Christy JH (1987) Competitive mating, mate choice and mating associations of brachyuran crabs. Bull. Mar Sci 41: $177-191$

Claxton WT, Govind CK, Elner RW (1994) Chela function, morphometric maturity, and the mating embrace in male snow crab, Chionoecetes opilio. Can J Fish Aquat Sci 51: $1110-1118$

Comeau M, Conan GY, Maynou F, Robichaud G, Therriault JC. Starr M (1998) Growth, spatial distribution, and abundance of benthic stages of the snow crab (Chionoecetes opilio) in Bonne Bay, Newfoundland, Canada. Can J Fish Aquat Sci 55:262-279

Conan GY, Comeau M (1986) Functional maturity and terminal molt of male snow crab, Chionoecetes opilio. Can J Fish Aquat Sci 43:1710-1719

Crespi BJ (1989) Causes of assortative mating in arthropods Anim Behav 38:980-1000

Diesel R (1988) Male-female association in the spider crab Inachus phalangium: the influence of female reproductive stage and size. J Crustac Biol 8:63-69

Donaldson WE, Adams AE (1989) Ethogram of behavior with emphasis on mating for the tanner crab Chionoecetes bairdi Rathbun. J Crustac Biol 9:37-53

Dufour R, Sainte-Marie B (1998) Crabe des neiges de l'estuaire et du nord du golfe du Saint-Laurent (zones 13 à 17). MPO Sciences, Rapp état stocks No. C4-01. MPO, MontJoli.

Dufour R, Bernier D, Brêthes JC (1997) Optimization of meat yield and mortality during snow crab (Chionoecetes opilio O. Fabriclus) fishing operations in eastern Canada. Can Tech Rep Fish Aquat Sci No. 2152

Elner RW, Beninger PG (1992) The reproductive biology of snow crab. Chionoecetes opilio: a synthesis of recent contributions. Am Zool 32:524-5.33

Elner RW, Beninger PG (1995) Multiple reproductive strategies in snow crab, Chionoecetes opilio: physiological pathways and behavioral plasticity. J Exp Mar Biol Ecol 193 93-112

Ennis GP, Hooper RG, Taylor DM (1990) Changes in the composition of snow crab (Chionoecetes opilio) participating in the annual breeding migration in Bonne Bay, Newfoundland. Can J Fish Aquat Sci 47:2242-2249

Grafen A, Ridley M (1983) A model of mate guarding. J Theor Biol 102:549-567

Haddon M (1994) Size-fecundity relationships, mating behaviour, and larval release in the New Zealand paddle crab, Ovalipes catharus (White 1843) (Brachyura, Portunidae). N Z J Mar Freshw Res 28:329-334

Hartnoll RG (1982) Growth. In: Abele LG (ed) The biology of Crustacea. Academic Press, New York, p 1.1-196

Hazlett BA (1972) Responses to agonistic postures by the spider crab Microphrys bicornutus. Mar Behav Physiol 1:85-92

Hooper RG (1986) A spring breeding migration of the snow $\mathrm{Crab}$, Chionoecetes opilio (O. Fabr.), into shallow water in Newfoundland. Crustaceana 50:257-264

Jivoff P (1997) Sexual competition among male blue crab, Callinectes sapidus. Biol Bull 193:368-380 
Jivoff P, Hines AH (1998) Female behaviour, sexual competition and mate-guarding in the blue crab. Callinectes sapidus. Anim Behav 55:589-603

Juanes F, Smith LD (1995) The ecological consequences of limb damage and loss in decapod crustaceans: a review and prospectus. J Exp Mar Biol Ecol 193:197-223

Kazmi QB, Tirmizi NM (1987) An unusual behaviour in box crabs (Decapoda, Brachyura, Calappidae). Crustaceana 53:313-314

Knuckey IA (1996) Maturity in male mud crabs, Scylla serrata, and the use of mating scars as a functional indicator. J Crustac Biol 16:487-495

Kon T, Sinoda M (1992) Zuwai crab population. Mar Behav Physiol 21:185-226

Laufer H, Ahl JSB, Taka P, Scott G, Stevens B, Munk JE, Payne SA (1996) Hormone and reproductive strategies in spider crabs with emphasis on commercially important species. In: Melteff $B$ (ed) Proceedings of the international symposium on biology, management, and economics of crabs from high latitude habitats, October 1995, Anchorage, Alaska. Lowell Wakefield Symp Ser, Alaska Sea Grant College Prog Rep No. 96-02, University of Alaska Fairbanks, p 383-387

Lee SY, Seed R (1992) Ecological implications of cheliped size in crabs: some data from Carcinus maenas and Liocarcinus holsatus. Mar Ecol Prog Ser 84:151-160

Lovrich GA, Sainte-Marie B, Smith BD (1995) Depth distribution and seasonal movements of Chionoecetes opilio (Brachyura: Majidae) in Baie Sainte-Marguerite, Gulf of Saint Lawrence. Can J Zool 73:1712-1726

Moriyasu M, Comeau M (1996) Grasping behavior of male snow crab Chionoecetes opilio (O. Fabricius, 1788) (Decapoda, Majidae). Crustaceana 69:211-222

Moriyasu M, Conan GY (1988) Aquarium observation on mating behavior of snow crab, Chionoecetes opilio. Int Counc Explor Sea CM 1988/K 9

Orensanz JM, Parma AM, Armstrong DA, Wardrup P (1995) The breeding ecology of Cancer gracilis (Crustacea: Decapoda: Cancridae) and the mating system of cancrid crabs. J Zool Lond 235:411-437

Paul AJ, Paul JM, Donaldson WE (1995) Shell condition and breeding success in Tanner crabs. J Crustac Biol 15:4?6-480

Paul JM, Paul AJ (1996) A note on mortality and injury rates of male Chionoecetes bairdi (Decapoda, Majidae) competing for multiparous mates. In: Melteff B (ed) Proceedings of the international symposium on biology, management, and economics of crabs from high latitude habitats, October 1995, Anchorage, Alaska. Lowell Wakefield Fish Symp Ser, Alaska Sea Grant College Prog Rep No. 96-02, University of Alaska Fairbanks, p 343-348

Pelletier N, Fraser A, Gauthier D, Laviolette M, Moriyasu M (1998) Mise en oeuvre d'une méthode pour l'analyse biochimique du mécanisme d'accouplement chez le crabe des neiges (Chionoecetes opilio). Rapp Tech Can Sci Halieutiques Aquat No. 2200

Reid DG, Abelló P, Warman CG. Naylor E (1994) Size-related mating success in the shore crab Carcinus maenas (Crustacea: Brachyura). J Zool Lond 232:397-407

Reid DG, Abelló P, Kaiser MJ, Warman CG (1997) Carapace colour, inter-moult duration and the behavioural and physiological ecology of the shore crab Carcinus maenas. Estuar Coast Shelf Sci 44:203-211

Ricker WE (1984) Computation and uses of central trend lines. Can J Zool 62:1897-1905

Ridley M (1983) The explanation of organic diversity. The comparative method and adaptations for mating. Clarendon Press, Oxford

Editorial responsibility: Gareth Harding (Contributing Editor), Dartmouth, Nova Scotia, Canada
Ridley M, Thompson DJ (1979) Size and mating in Asellus aquaticus (Crustacea: Isopoda). Z Tierpsychol 51:380-397

Rowe L (1992) Convenience polyandry in a water strider: foraging conflicts and female control of copulation frequency and guarding duration. Anim Behav 44:189-202

Sainte-Marie B (1993) Reproductive cycle and fecundity of primiparous and multiparous female snow crab, Chionoecetes opilio, in the Northwest Gulf of Saint Lawrence. Can J Fish Aquat Sci 50:2147-2156

Sainte-Marie B, Carrière C (1995) Fertilization of the second clutch of snow crab. Chionoecetes opilio, mated once or twice after their molt to maturity. Fish Bull US 93:758-763

Sainte-Marie B, Hazel F (1992) Moulting and mating of snow crabs, Chionoecetes opilio (O. Fabricius), in shallow waters of the northwestern Gulf of Saint Lawrence. Can J Fish Aquat Sci 49:1282-1293

Sainte-Marie B, Lovrich GA (1994) Delivery and storage of sperm at first mating of female Chionoecetes opilio (Brachyura: Majidae) in relation to size and morphometric maturity of male parent. J Crustac Biol 14:508-521

Sainte-Marie B, Raymond S, Brêthes JC (1995) Growth and maturation of the benthic stages of male snow crab, Chionoecetes opilio (Brachyura: Majidae). Can J Fish Aquat Sci 52:903-924

Sainte-Marie B, Sévigny JM, Smith BD, Lovrich GA (1996) Recruitment variability in snow crab (Chionoecetes opilio): pattern, possible causes, and implications for fishery management. In: Melteff B (ed) Proceedings of the international symposium on biology, management, and economics of crabs from high latitude habitats, October 1995, Anchorage, Alaska. Lowell Wakefield Fish Symp Ser, Alaska Sea Grant College Prog Rep No. 96-02, University of Alaska Fairbanks, p 451-478

Sainte-Marie B, Sévigny JM, Gauthier Y (1997) Laboratory behavior of adolescent and adult males of the snow crab (Chionoecetes opilio) (Brachyura: Majidae) mated noncompetitively and competitively with primiparous females. Can J Fish Aquat Sci 54:239-248

Smith IP, Huntingford FA, Atkinson RJA, Taylor AC (1994) Mate competition in the velvet swimming crab Necora puber: effects of perceived resource value on male agonistic behavior. Mar Biol 120:579-585

Smith LD (1992) The impact of limb autotomy on mate competition in blue crabs Callinectes sapidus Rathbun. Oecologia 89:494-501

Somerton DA, Meyers WS (1983) Fecundity differences between primiparous and multiparous female Alaskan Tanner crab (Chionoecetes bairdi). J Crustac Biol 3: $183-186$

Stevens BG, Donaldson WE, Haaga JA, Munk JE (1993) Morphometry and maturity of paired tanner crabs, Chionoecetes bairdi, from shallow- and deepwater environments. Can J Fish Aquat Sci 50:1504-1516

Urbani N, Sainte-Marie B, Sévigny JM, Zadworny D, Kuhnlein U (1998a) Sperm competition and paternity assurance during the first breeding period of female snow crab Chionoecetes opilio (Brachyura: Majidae). Can J Fish Aquat Sci 55:1104-1113

Urbani N, Sévigny JM, Sainte-Marie B, Zadworny D, Kuhnlein U (1998b) Identification of microsatellite markers in the snow crab Chionoecetes opilio. Mol Ecol 7:357-358

Wada S, Sonoda T, Goshima S (1996) Temporal size covariation of mating pairs of the hermit crab Pagurus middendorffii (Decapoda: Anomura: Paguridae) during a single breeding season. Crustac Res 25:158-164

Watson J (1972) Mating behavior in the spider crab, Chionoe cetes opilio. J Fish Res Board Can 29:447-449 